\title{
Uma problemática da Arqueologia e da História: a cidade e seus territórios
}

A problematic of the Archaeology and History: the city and its territories

Arno Alvarez Kern*

\begin{abstract}
Resumo
Os estudos que atualmente se desenvolvem sobre a temática da cidade apresentam como objetivo principal aprofundar as reflexões e os conhecimentos históricos sobre esses microcosmos em que muitas sociedades do passado escolheram viver. Este trabalho tem como objetivo pesquisar a originalidade, as causas do desenvolvimento e as mudanças ocorridas nessa história de longa duração. A urbanidade, ou seja, uma maneira de ser característica das aglomerações urbanas, está diretamente relacionada à história de longa duração das civilizações e, certamente, com a história das sociedades ibero-americanas. Esse é um fenômeno que nós, historiadores e arqueólogos da atualidade, julgamos não apenas importante, mas mais fundamental em nosso modo de vida social do que os próprios homens da época poderiam pensar em relação às suas próprias sociedades.
\end{abstract}

Palavras-chave: Arqueologia urbana; História da cidade; Problemáticas científicas.

\begin{abstract}
The current studies on the theme of the city have as main objective to deepen the reflections and historical knowledge about these microcosms in which many societies of the past have chosen to live. This paper aims to investigate the originality, the causes of development and the changes that have occurred in this long lasting history. Urbanity, in other words, a way of being characteristic of urban agglomerations, is directly related to the long history of civilizations and, certainly, to the history of Ibero-American societies. This is a phenomenon that we, historians and archaeologists of the present time, deem not only important, but more fundamental in our social way of living than the men at that time could think about their own societies.
\end{abstract}

Keywords: Urban archeology; City history; Scientific problematic.

"Não são as pedras que fazem a cidade, mas os homens." Isidoro de Sevilha (século VII d.C.).

\section{Introdução}

Os estudos que atualmente se desenvolvem sobre a temática da cidade apresentam como objetivo principal aprofundar as reflexões e os conhecimentos históricos sobre esse microcosmos em que muitas das sociedades do passado

\footnotetext{
* Doutor em Arqueologia Métodos e Técnicas pela Ecole des Hautes Études en Sciences Sociales (EHESS - França). Professor titular aposentado dos Cursos de Graduação e de Pós-Graduação em História da Universidade Federal do Rio Grande do Sul (UFRGS) e da Pontifícia Universidade Católica do Rio Grande do Sul (PUCRS). Pesquisador do Centro de Estudos e Pesquisas Arqueológicas (CEPA) da Pontifícia Universidade Católica do Rio Grande do Sul (PUCRS). Pesquisador nível 1A do CNPq. Historiador e arqueólogo. E-mail: aakern40@gmail.com.
} 
escolheram viver. Trata-se de pesquisar a originalidade, as causas do desenvolvimento e as mudanças ocorridas nessa história de longa duração. A urbanidade, ou seja, uma maneira de ser característica das aglomerações urbanas, está diretamente relacionada à história de longa duração das civilizações (ROCHE, 1990), e, certamente, com a história das sociedades ibero-americanas. Este é um fenômeno que nós, arqueólogos dos sítios históricos, julgamos não apenas importante, mas ainda mais fundamental em nosso modo de vida social do que os próprios homens da época poderiam pensar em relação às suas próprias sociedades (RONCAYOLO, 1993; LONIS, 2003; ROUX, 2004). Este trabalho é um estudo das questões científicas sobre as cidades.

\section{As diversas variáveis para o estudo das cidades}

Em um primeiro momento, trata-se de conhecer em maior profundidade a comunidade dos homens que construíram as cidades e que, dentro delas, passaram a se reunir e a se organizar enquanto comunidades diferentes das demais sociedades. Esses estudos podem ser realizados a partir dos elementos da cultura material que comprovam os episódios de sua organização ou em documentos iconográficos de época, tais como os planos laboriosamente desenhados de suas formas urbanas e que são representações espaciais de extraordinária importância para a reconstituição de seus processos históricos. Devemos igualmente nos basear nas fontes escritas históricas que estabeleceram as normas da vida urbana e suas instituições. Os documentos históricos podem ter origens muito diversificadas, como é o caso do poema homérico Ilíada para o estudo de Tróia, ou dos escritos dos missionários jesuítas para os povoados missioneiros no Rio da Prata.

As fontes escritas, materiais e iconográficas, são quase inesgotáveis: arquivos eclesiásticos, arquivos municipais, antigos planos urbanos, iconografias de época, velhas fotografias, textos narrativos literários, ruínas de edificações e vestígios da antiga estrutura viária. Como as cidades são, também, verdadeiros arquivos de cultura material produzidos ao longo dos séculos e milênios, não podemos ignorar a contribuição fundamental dos vestígios obtidos nas escavações arqueológicas: sedimentos de estratigrafias antigas, vestígios de objetos artesanais, remanescentes arquitetônicos enterrados. Não se trata apenas de uma possível reconciliação entre a arqueologia e a história, como já se afirmou (ETIENNE, 2000, p. 18-19), mas o estabelecimento de uma possível e necessária complementaridade entre essas duas ciências. 
A série de dados arqueológicos e históricos de que dispomos atualmente oferece a possibilidade de uma análise de conjunto e de uma síntese histórica capazes de ampliar as perspectivas e os horizontes. A partir de novas interpretações, podemos estimular questões científicas originais e renovar as opiniões ainda muito limitadas. É necessário reconhecer que, sem esse estudo analítico global e sem uma síntese geral, todos esses dados arqueológicos e escritos, dispersos nos sítios arqueológicos e nas publicações, só têm valor histórico muito limitado, mesmo que venham muitas vezes acompanhados por datações absolutas de sincronismo histórico, ou cronologias relativas (KERN, 1998, p. 22).

O termo polis é polissêmico e utilizado por Homero ora no sentido de uma aglomeração urbana, ora no de assembleia do conjunto de seus habitantes. Acompanhando a vida das cidades, a partir de seus documentos históricos, nós podemos claramente perceber como "[...] a historiografia das cidades nasce com elas; é uma necessidade, um modo de afirmar a originalidade das práticas sociais." (ROCHE, 1990, p. 89; KERN, 1998b, p. 127). Vemos, também, como as experiências de gerações anteriores serviram de base para definir tradições urbanas aparentemente novas e originais. No século 17, os jesuítas fundam as primeiras aglomerações urbanas coloniais no Rio da Prata, com uma clara designação ao conceito greco-romano de civis, quando afirmam que os indígenas deveriam ser reduzidos à igreja e à vida civil ("ad ecclesiam et vitam civilem esset reducti'). Julgavam que, para uma perfeita cristianização, era necessário inicialmente reduzir os indígenas ao novo espaço urbano, pois só ali seriam levados a viver como cidadãos de maneira política (na polis), como na antiga cidadeestado grega ou romana.

A arqueologia pode nos fornecer uma série de indícios da formação histórica de inúmeras cidades, evidenciando a organização dos espaços, por um lado, e as mudanças ocorridas na cultura material, tais como as alterações nos hábitos cotidianos das comunidades urbanas, por outro lado. Entre os diversos campos de atuação da arqueologia atualmente desenvolvidos e promissores, destaca-se o da arqueologia urbana. Nessa prática arqueológica, destacam-se as pesquisas nos territórios dominados pelas cidades e os estudos cronológicos nas estratigrafias encontradas. Ao acompanhar a renovação dos centros históricos das cidades após as grandes guerras mundiais e, sobretudo, na década de setenta do século passado, a arqueologia urbana se beneficiou de um importante enriquecimento - em qualidade e em quantidade - dos conjuntos documentais da cultura material. Diversos interesses temáticos têm atraído a atenção 
dos arqueólogos que trabalham nos sítios urbanos: análises biológicas das populações, aprovisionamento da água, a morfologia da cidade e sua organização social, bem como a longa duração de sua existência. A arqueologia urbana está constituindo uma base de documentos que deverá conduzir, nos próximos decênios, a um conhecimento das estruturas, dos equipamentos e do meio urbano, estabelecido sobre dados variáveis e confiáveis (GALINIE, 1990).

Devemos, também, levar em conta, em um segundo momento, as atuações dos grupos de homens que se reuniram enquanto comunidades urbanas. Muitos deles já estavam bem organizados como etnias em comunidades com uma tradição cultural secular. Em seus primórdios, estes grupos não apenas construíram as suas cidades. Muitas vezes, as cidades já estabelecidas receberam outros grupos que ali vieram morar. Nessas cidades construídas por outras gerações, esses novos grupos terminaram por se adaptar, e igualmente introduziram inovações a partir de suas culturas. Essas inúmeras gerações de cidadãos tentaram construir culturalmente memórias e histórias sobre as vicissitudes de suas cidades, exaltando as suas virtudes e transmitindo as suas lembranças. Os estudos atuais das cidades, entretanto, devem ultrapassar essas inúmeras histórias locais e particulares, partindo para uma perspectiva mais ampla, em uma história de longa duração, que visa responder a importantes questões sobre o papel, a importância e o dinamismo dessas aglomerações urbanas (ROUX, 2004), desde as etapas pré-urbanas até as cidades perfeitamente desenvolvidas.

A arqueologia, ao recolher nos arquivos do solo a sua documentação, nos convida "[...] a desenvolver temas de reflexão que tem por objetivo explicar como as aglomerações de origem antiga pouco a pouco adquiriram sua identidade atual." (GALINIE, 1990, p. 466). Se a arqueologia da cidade tem uma longa história de realizações, desde as escavações pioneiras de Tróia e Pompeia, muito ainda resta a fazer para o desenvolvimento de uma arqueologia na cidade ocupada ainda atualmente (GALINIE; ROYO, 1998).

Em um terceiro momento, temos de compreender que não estamos às voltas com um universo imutável. Trata-se de compreender uma longa história que apresenta temporalidades diferentes, nas quais as cidades não mantiveram sempre o mesmo aspecto em todas as épocas. Trata-se de uma história de sociedades humanas ao longo de um tempo histórico, que dura já 10.000 anos. Essa evidência nos permite discernir como as cidades se inseriram e se adaptaram aos contextos históricos variados em um processo histórico complexo na antiguidade, no mundo medieval e na modernidade. 
Devemos igualmente levar e em conta que essas cidades são cercadas por territórios e por redes de cidades menores e subordinadas, de uma maneira quase sempre informal. Essas pequenas cidades, habitualmente associadas às maiores ou suas vassalas nas relações de poder, são participantes constantes dos intercâmbios comerciais e culturais que se desenvolvem nas regiões (RONCAYOLO, 1993). Os territórios relacionados a uma cidade dependem, é claro, de realidades, de mecanismos ou de escalas bem diferentes.

No campo da arquitetura ocorreu uma nova orientação dos estudos sobre o urbanismo. No passado, os estudos arquitetônicos de urbanismo se limitavam aos estudos estáticos sobre os planos urbanos. Entretanto, a partir dos anos setenta, as pesquisas sobre os processos históricos das formas urbanas começaram a ter uma importância muito grande. Isto ocorreu quando o planejamento urbano, sobretudo a recuperação dos centros históricos de antigas cidades, foi forçado a atender às necessidades crescentes de nossa sociedade. Os novos desafios mostraram aos arquitetos que, para uma boa qualificação profissional, uma valorização crítica do passado era um ponto de partida fundamental para as novas exigências do planejamento. Mas, em contrapartida, havia também um crescente interesse por temáticas relacionadas às histórias locais (MORRIS, 1984). Atualmente destaca-se em suas análises a vantagem do estudo do desenvolvimento das "formas urbanas" ao longo dos processos históricos, predominando sobre as análises estáticas dos planos urbanos até então usuais. Se formos levar em conta que a grande maioria de núcleos urbanos nunca foi projetada, isso faz com que as referências a "planejamento" urbano ou a "urbanismo" sejam muitas vezes inexatas (MORRIS, 1984).

Finalmente devemos compreender que montar um banco de dados com evidências documentais e reconstituir sinteticamente histórias de estudos de caso, entretanto, não esgotam as possibilidades da reconstituição dos processos históricos de longa duração. As abordagens possíveis sobre os estudos das cidades é igualmente uma forma de acompanhar os inúmeros debates que se travam entre os pesquisadores, o que tornou os questionamentos mais amplos e renovados.

\section{Os questionários científicos}

Atualmente, o pesquisador não tem a pretensão de contar tudo o que se passou, em toda a história da humanidade. 
Está consciente de que escolhe, nesse passado, aquilo de que fala e, assim fazendo, coloca, a esse passado, questões seletivas. Por outras palavras, constrói seu objeto de estudo, delimitando não só o período, o conjunto dos acontecimentos, mas também os problemas colocados por este período e por esses acontecimentos, e que terá que resolver. Não pode, portanto, escapar a um mínimo de conceptualização explícita: a boa questão, o problema bem colocado são mais importantes - e são mais raros [...]. (FURET, 1975, p. 76).

Portanto, tentamos responder a diversas questões científicas que foram surgindo ao sabor das tendências da pesquisa e dos debates.

Devemos saber responder, por exemplo, a toda uma série de novos problemas propostos pelos arqueólogos, decorrentes das pesquisas desenvolvidas desde as escavações de Pompeia e de Tróia, até os povoados missioneiros modernos do Rio da Prata. É exatamente quando tentamos nos referir às origens das cidades e ao seu processo de desenvolvimento que percebemos a importância da arqueologia para as análises.

Podemos inicialmente destacar duas questões fundamentais que surgem precisamente das transformações por que passam essas aglomerações urbanas (ETIENNE, 2000). Ocorre uma continuidade ou uma descontinuidade entre o mundo do passado e uma situação nova? Estamos diante de um corte radical, uma transformação rápida ou um desenvolvimento progressivo? Questões muito específicas como essas citadas resultam dos procedimentos arqueológicos e da análise dos materiais.

A arqueologia também se interessa pelos critérios relacionados ao aparecimento das cidades. Entre eles, podemos destacar alguns que podem ser levados em conta nas pesquisas dos arqueólogos para denominar um determinado sítio como sendo uma cidade:

a) Um dos critérios mais utilizados é o da alta concentração de indivíduos em um sítio arqueológico, o que nos indica o grau de ocupação humana. Os arqueólogos tendem a não utilizar essa denominação para um pequeno conjunto de casas, mas sim para aglomerações urbanas de uns 50 hectares. Entretanto, como cada cidade pode ser uma resultante específica de uma concentração de diversos homens em uma determinada paisagem, sabemos que apenas esse critério poderá ser insuficiente.

b) Por isso, outro importante critério é o da especialização de diversas atividades artesanais. Nos sítios urbanos, aparentemente a produção de cerâmica, de 
esculturas ou de produtos metalúrgicos podem estar localizados longe das fontes de matérias primas, mas próximo a mercados ocasionais ou permanentes.

c) Outro critério é o da arquitetura pública monumental, que dá origem a edifícios de uso comum construídos em espaços públicos como a ágora ou a plaza maior, e que podem abrigar órgãos administrativos (as assembleias e os conselhos municipais) ou instituições religiosas (os templos).

d) Os túmulos das necrópoles e as habitações familiares de uma cidade podem nos indicar a riqueza ou pobreza dos cidadãos e nos levam a outro critério essencial: o de uma estratigrafia social mais complexa.

e) As inscrições votivas e funerárias, os grafiti parietais, obras poéticas e filosóficas, as legislações inscritas em placas públicas e os documentos comprovando as relações políticas internacionais são evidências arqueológicas de que a escrita e seu uso pela população pode nos indicar a cidade.

f) Muitas obras de arte podem ser encontradas nos sítios arqueológicos urbanos, comprovando que o desenvolvimento das atividades artísticas é outro dos critérios que podem ser utilizados. Recipientes cerâmicos ou de metal ricamente ornamentados, esculturas e pinturas de alta qualidade são alguns exemplos do artesanato de alto nível que os arqueólogos podem encontrar nos sítios históricos que escavam.

g) Um critério muito importante nos é indicado pelas relações de trocas comerciais externas com outras cidades, que nos indicam grupos de mercadores que circulam entre portos e mercados com produtos capazes de atender aos hábitos tradicionais das populações ou ao desejo de novidades das elites locais.

h) Finalmente, o estudo atual dos territórios de cidades nos abre uma série de perspectivas fecundas, combinando a aplicação de modelos espaciais e a abertura para a geografia e a ecologia dos homens.

Podemos afirmar de maneira segura que os arqueólogos podem nos fornecer os elementos da cultura material "[...] susceptíveis de precisar a natureza dos fenômenos que se estabelecem [...]" (ETIENNE, 2000, p. 65), para cada um desses critérios. Nenhum deles é suficiente por si só, mas a convergência de diversos testemunhos materiais nos autoriza as interpretações que podemos apresentar como produtos intelectuais da pesquisa. 
Podemos afirmar, com relativa certeza, que muito antes do nascimento de uma cidade plenamente constituída, a arqueologia pode se utilizar dos critérios destacados acima e nos evidenciar, a partir de formas pré-urbanas a emergência de uma concentração urbana, o início da nova cidade.

Os historiadores destacaram recentemente uma série de questões científicas que julgam fundamentais para a compreensão do fenômeno urbano. Entre elas, podemos destacar:

a) Do ponto de uma história comparada e de uma discussão conceitual sobre as cidades, quais são as variáveis a serem levadas em conta e que podem distinguir ou aproximar as formas de organização cultural, social e política das cidades da antiguidade, as medievais ou as modernas?

b) Quando surgem as cidades, quais os modelos e quais os fatores que atuam em suas origens, e como se mantêm ou são substituídos quando das transformações que ocorrem ao longo do tempo histórico?

c) Viver em uma cidade, manter a sua coesão evitando as crises internas, defender seus muros contra o inimigo externos, dirigir e administrar o conjunto de seus cidadãos, obter o básico de sua alimentação e da água tão necessária, produzir artesanalmente, comerciar por rotas terrestres e marítimas?

d) O cenário sempre cambiante da história urbana: como os homens tiveram condições favoráveis ou desfavoráveis para a produção da cultura (filósofos, escultores, músicos, teatrólogos, poetas e historiadores), bem como construir torres e muralhas, praças e ruas, templos e palácios, portos e aquedutos, em um espaço que sempre foi também material?

e) Qual a importância da etnia (do povo) que habita as cidades e dos diversos setores/grupos sociais em que esta etnia se divide na constituição da cidade? Quais as suas mobilidades verticais e horizontais? Quais os setores marginalizados?

f) Como se defrontam e se encontram na cidade o poder e o saber? E como atuaram nesse pequeno mundo os elementos religiosos (grandes sacerdotes, baixo clero, membros de congregações), políticos (administradores, líderes militares, membros dos conselhos e assembleias) e culturais (técnicos, artesãos, engenheiros) na fundação e na organização da cidade? 
g) Alianças e conflitos: nos complexos quadros das relações regionais e internacionais, como podemos compreender o papel desempenhado pelas cidades do contexto histórico no qual estavam inseridas?

Essa variedade de questões, salientadas por muitos autores atuais, denotam algumas das abordagens que ultrapassam as visões reducionistas do passado (LONIS, 2003, p. 3), evidenciando as múltiplas dimensões desse complexo universo das poleis, sejam elas antigas, medievais ou modernas. Elas também nos permitem compreender o cenário ambiental e o contexto político, social, cultural, religioso e econômico em que viveram muitos homens cujos esforços e realizações nos permitem tecer considerações sobre a cidade. As dificuldades que possamos encontrar na busca de soluções para essas múltiplas questões não são uma evidência da nossa incapacidade de compreender, mas deve ser interpretada como um estímulo que nos impele para a reflexão mais aprofundada sobre esse fenômeno tão importante para toda a nossa história ocidental (ROUX, 2004).

\section{Um busca das respostas: as interpretações atuais}

As tentativas de encontrar soluções para algumas dessas questões levaram muitos estudos a interpretações variadas, e podem ser colocadas em dúvida hoje em dia.

Por exemplo, uma das ideias muito difundidas nas publicações reduz a cidade ao conjunto das edificações que a compõem, sendo antes de tudo um tema arquitetural, o que nos mostra como é sempre um alerta a ideia de Isidoro de Sevilha, citada no início deste estudo. Mesmo se na época moderna foi deliberada a implantação de planos urbanos, nascidos de maneira racional, não podemos deixar de reconhecer as estruturas anteriores da cidade e as épocas em que elas se desenvolvem segundo outras variáveis e outras preocupações. A partir das datações de radio-carbono $(\mathrm{C} 14)$ sabemos que esta é uma história de longuíssima duração se levarmos em conta que a primeira delas, Jericó, já tem dez mil anos desde a sua fundação. Na maioria dos casos conhecidos, os homens que construíram pouco a pouco as suas cidades sempre se consideraram como atores do processo e não meros residentes das estruturas construídas em mármore, tijolo ou madeira.

Deve ser lembrado que muitos estudiosos, ao tentarem explicar a história da cidade no passado mais remoto, tentaram perceber inicialmente o predomínio de cidades com conotações arcaicas e dominadas pelos elementos religiosos e comunitários, que 
teriam sido gradualmente substituídas em épocas mais recentes por cidades de características mais clássicas, nas quais predominaram os elementos políticos e as maiores liberdades individuais (LONIS, 2003). Atualmente, em todos os estudos sobre a cidade, sabemos que se trata sempre de duas tendências históricas que são contemporâneas e que variaram em questão de graus e nuances em épocas distintas. A história das cidades não pode ser reduzida a um modelo simples, nem a esquemas rígidos, antagônicos e evolucionistas. Cada vez que tentarmos examinar esses esquemas, terminamos nos dando conta de que na história as realidades foram muito mais complexas, e os exemplos que hoje conhecemos apontam para uma maior diversidade (ROUX, 2004).

Nas abordagens atuais, por exemplo, podem ser outras as variáveis destacadas. Em primeiro lugar, é impossível compreender a complexidade destes microcosmos urbanos, sem nenhuma referência ao contexto internacional ou regional, sempre tão presentes na documentação. Históricos ou arqueológicos, os estudos contextuais são abordagens teóricas de médio alcance, ultrapassando os estudos pontuais sem atingir as visões especulativas da totalidade do processo histórico da humanidade. Eles englobam tanto o cenário do ambiente natural como os aspectos sociais e culturais dos personagens históricos em presença. Segundo Hodder (1986), uma análise contextual arqueológica pode ser assim caracterizada:

\footnotetext{
Numa primeira abordagem, o contexto a ser analisado se refere tanto ao contexto ambiental como ao das sociedades presentes na área em estudos. Numa segunda abordagem, o contexto se refere tanto aos aspectos arqueológicos da cultura material quanto aos seus significados simbólicos. Não podemos, atualmente, reduzir o desenvolvimento urbano a um modelo simples, funcionando em todo o Ocidente, tal como Henry Pirenne e seus alunos propuseram. (HODDER, 1986, p. 118).
}

Duas ênfases analíticas importam atualmente, segundo Roche (1990). Em primeiro lugar, termos a coragem de "[...] reabrir o dossier sem a priori e com o espírito de confrontação imposto pelo estudo da diversidade social urbana a longo termo.” Em segundo lugar, levarmos em conta, de maneira corajosa, “[...] que é necessário comparar classificações várias que apelem para diferentes variáveis [...] que sejam seguidas ao longo da sua evolução e confrontadas num espaço concreto." (ROCHE, 1990, p. 92).

Em terceiro lugar, a própria tipologia das cidades mudou. Somos hoje obrigados a reconhecer pelo menos três tipos diferentes de cidades a serem estudadas: a) as cidades antigas e já tradicionais em uma região (Atenas, Roma, Paris e Madri), e que se 
transformaram em capitais de reinos ou de impérios (urbs), decaem com o tempo e podem se revigorar mais tarde; b) as cidades novas fundadas em expansões comerciais ou como colônias militares associados aos fenômenos das conquistas (as cidades antigas da Sicília e os povoados missioneiros modernos); c) as cidades de nativos já existentes nas áreas conquistadas e que pouco a pouco se inserem e se integram a essas novas expansões ou às suas zonas de influências, como Duga (Tunísia) e as citiânias ao norte de Portugal.

A busca das respostas às questões científicas colocadas recentemente, bem como o resultado dos debates travados entre os pesquisadores, deram realce a outras variáveis importantes que devem ainda ser aprofundadas. No passado se deu ênfase aos conflitos políticos das cidades ou ao surgimento do mundo dos artesãos e mercadores. Hoje, teríamos que explorar ainda a importância dos fenômenos religiosos e destacar a influência dos aspectos ideológicos. Mas, no plano da organização social, não deveríamos jamais esquecer de estudar o papel de outras categorias sociais, como os estrangeiros e os escravos, privilegiar a participação das famílias e das ligações familiares por meio do papel das mulheres.

\section{Considerações finais}

A arqueologia e a história podem desempenhar um papel de extraordinária importância para a compreensão dos processos globais de mudança sociocultural das sociedades que habitaram as cidades no passado, bem como para identificar seu "ethos". Uma pesquisa dessa natureza atualmente se desenvolve a partir da análise de múltiplas e complexas informações obtidas na documentação do passado. Algumas delas evidenciam as adaptações culturais aos contextos ambientais. Outras nos indicam os elementos materiais da cultura voltados para aspectos técnicos e econômicos da sociedade. Muitos deles, predominantemente históricos, sugerem-nos os aspectos sociopolíticos e ideológicos. Estas duas ciências em construção, a arqueologia e a história, têm como objetivo o estudo sincrônico e diacrônico simultâneo das diferentes etnias existentes no passado e organizadas como comunidades urbanas. As pesquisas se fundamentam no exame crítico da documentação escrita e dos vestígios materiais do passado, que sobreviveram aos fenômenos de destruição naturais ou antrópicos (KERN, 1998, p. 17). 
Trata-se de uma ligação intrínseca entre a arqueologia e a história: de uma arqueologia capaz de proporcionar fontes específicas e de uma história da cultura material das civilizações. 


\section{REFERÊNCIAS}

ETIENNE, Roland, et all. Archéologie historique de la Grèce antique. Paris: Ellipses, 2000 .

GALINIÈ, Henri. L'archéologie urbaine. In: MOHEN, Jean-Pierre; BRIARD, Jacques; GOUDINEAU, Christian; et al. L'Archéologie de la France. Paris: Flammarion, 1990.

FURET, François. De l'histoire-récit à l'histoire-problème. In: FURET, François. L'atelier de l'histoire. Paris: Chaps/Flammarion, 1975. [Tradução portuguesa: A oficina da história. Lisboa: Editora Gradiva, s/d.].

GALINIÈ, Henry; ROYO, Manuel. A arqueologia à conquista da cidade. In: BOUTIER, Jean; DOMINIQUE, Julia. Passados recompostos. Rio de Janeiro: Editora FGV; Editora UFRJ, 1998.

HODDER, Ian. Reading the past. Current approaches to interpretation in archaeology. Cambridge: Cambridge University Press, 1986.

KERN, Arno Alvarez. Aspectos teóricos e metodológicos da Arqueologia Histórica do Rio da Prata. Anais... VIII Congresso Nacional de Arqueologia Uruguaia, Maldonado, out. 1995.

KERN, Arno Alvarez. Arqueologia histórica missioneira. Porto Alegre: Editora PUCRS, 1998.

KERN, Arno Alvarez. Análise do plano urbano das Missões jesuítico-Guaranis. Anais... VI Jornadas Internacionais sobre as missões jesuíticas. Cascavel: UNIOESTE, 1998b.

LONIS, Raoul. La cité dans le monde grec. Paris: Nathan Université, 2003.

MORRIS, Anthony Edwin James. História de la forma urbana. Desde sus orígenes hasta la Revolución Industrial. Barcelona: Editorial Gustavo Gili, 1984.

ROCHE, Daniel. Cidade. In: LE GOFF, Jacques; CHARTIER, Roger; REVEL, Jacques. A nova história. Coimbra: Editora Almedina, 1990.

RONCAYOLO, Marcel. La ville et ses territoires. Paris: Gallimard, 1993.

ROUX, Simone. Le monde des villes au Moyen Âge. Paris: Hachette, 2003. 